\title{
The impact of biochar dosing with simultaneous fertilization with a biogas plant digestate on the volumetric density of soil
}

\author{
Jakub Sikora $^{1 *}$, Urszula Sadowska ${ }^{1}$, Agnieszka Klimek-Kopyra ${ }^{2}$, and Maciej Gliniak ${ }^{1}$ \\ ${ }^{1}$ University of Agriculture in Krakow, Faculty of Production and Power Engineering1, ul. Balicka \\ 116B, 30-149, Poland \\ ${ }^{2}$ University of Agriculture in Krakow, Faculty of Agriculture and Economics, al. Mickiewicza 21, 31 - \\ 120, Poland
}

\begin{abstract}
The paper analyses the impact of biochar on the volumetric density of the soil, with simultaneous fertilization with an agricultural biogas plant digestate. For the purpose of the research, 10 experimental fields were prepared for the study, in accordance with good agricultural practice. To verify the results, a single-factor variance analysis was performed, which demonstrated a significant differentiation between the dosing of the biochar and the values of the volumetric density of the soil. Using the digestate simultaneously with the biochar addition further increased the disparity in the soil's volumetric density between the respective biochar doses.
\end{abstract}

\section{Introduction}

Changes in soil pore size distribution, and in overall soil porosity, are the direct effect of changes in soil density. Porosity affects the spatial distribution of soil water, its availability for plants, as well as micro- and macro diffusion of oxygen in the soil. Moreover, the spatial distribution of the solid phase and water influences the soil's thermal features, and related temperature distribution in its structure. It also affects the forces combining the elements of the soil structure. Oxygen content, water available in the soil, and its temperature, as well as mechanical resistance to roots all have a direct impact on the development of vegetation, and the yield. The figure below presents a simplified diagram of the impact of density and general porosity of the soil on its physical properties and yielding of plants [1]. Optimal soil density is therefore a multi-faceted concept, which requires an

\footnotetext{
* Corresponding author: jakub.sikora@urk.edu.pl
} 
explanation of the relationship between the degree of soil density and its other features that condition the development of plants. The issue is the backdrop for the analysis of the impact of biochar on the physicochemical properties of soil [2].

One of the key segments of plant agrotechnics is fertilization as mineral and organic fertilizers affect the chemical, biological and physical properties of soils, shaping its productiveness, richness and fertility. The most common organic fertilizer used in agriculture is manure, which is considered one of the best fertilizers in terms of impact on the soil environment[10]. However, due to the increasing share of cereals in the distribution of crops, and the reduction of stocking density in agricultural holdings, its deficit is more and more often experienced. Manure can be replaced with intercrop, straw or vermicompost, among others. One of the characteristic features of using organic fertilization is its impact in subsequent years [3-5].

Research by Wacławowicz R. [5,6], to determine the effect of organic fertilization, in particular with manure, vermicompost, intercrop and nitrogen, on the volumetric density and porosity of the soil, demonstrated that the volumetric density of the soil determined after winter barley harvest was significantly differentiated only in terms of organic fertilizers, in the 25-30 cm layer. All organic fertilizers significantly reduced the volumetric density of soil in a given soil layer. Similar tendencies in changes were noted in the layer of $15-20 \mathrm{~cm}$. Organic fertilization also slightly contributed to the change in the volumetric density of soil at a depth of $5-10 \mathrm{~cm}$. The use of intercrop, straw and beet leaves resulted in a slight decrease in volumetric density, while the use of manure and vermicompost resulted in a slight increase in volumetric density. Immediately after winter barley harvest, the values of general soil porosity were significantly differentiated only in the $25-30 \mathrm{~cm}$ layer. The application of each of the tested types of fertilizers in the soil increased the total porosity of the soil. However, a statistically documented increase in porosity was observed only three years after manure plowing. In the $5-10 \mathrm{~cm}$ soil layer, no significant changes were observed, however, a slight reduction in the total porosity of the soil was noted, provided that manure or vermicompost was introduced into the soil three years earlier. A slight increase in total porosity of the soil was observed in the $15-20 \mathrm{~cm}$ layer, as a result of applying organic fertilizers. All the analyzed organic fertilizers were used to increase soil porosity, however, manure turned out to be the most beneficial $[6,7]$.

The digestate, also called biogas sludge, is a byproduct of agricultural biogas plants, originating from the process of methane fermentation of agricultural biomass. Due to the diversity of potential substrates for use in the agricultural biogas production, their origin, composition and technologies used, the physicochemical properties of agricultural digestate may be heterogeneous. It is assumed that the obtained digestate yield is $85-95 \%$ of the mass of substrates used for the process. In addition, the more organic easily fermenting substances there are in the raw material, the smaller the amount of digestate. The digestate consists mainly of unfermented fragments of organic matter, biomass of methane bacteria and minerals. The main parameter that characterizes the digestate is the content of: organic substances, dry matter, nitrogen, calcium, phosphorus and heavy metals. The digestate is an aqueous suspension with $2-5 \%$ dry matter content and a $\mathrm{pH}$ of approx. 7 . Dissolved in the solution are mineral and organic compounds. The amount of total nitrogen in the digestate is approx. $2-3 \%$ of the raw mass. Since nitrogen is significantly ammonified during the anaerobic fermentation, it is predominantly present in the digestate in the form of ammonium nitrogen, reaching up to $85 \%$ [6-8].

The International Biochar Initiative defines biochar as: fine-grained carbonate with high carbon content and low susceptibility to degradation. Biochar is obtained in the process of pyrolysis of plant biomass and organic waste. Comparing biochar and carbonate in terms of their physicochemical properties, it can be stated that they are essentially the same substrate 
$[8,9]$. The only significant difference between these materials is their use. While carbonate is used as a renewable fuel in energy production processes, biochar is used, e.g. for carbon sequestration in the soil, for remediation of contaminated land and other environmental purposes. Used in farming to improve land properties, biochar is also known as agrocarbonate. Please note that the word "biochar" indicates the biological origin of materials used in the pyrolysis process [9-11].

The aim of the study was to determine the impact of biochar addition on the volumetric density of soil, with simultaneous fertilization with digestate from agricultural biogas plants.

\section{Material and methods}

Studies on the impact of biochar addition on soil density with simultaneous fertilization with digestate from agricultural biogas plants were carried out on experimental fields of the Agricultural University in Krakow. The digestate came from an agricultural biogas plant located in Wielopole, Dabrowa District, Małopolskie Province. This biogas plant is based on input from animal production, fermenting pig manure with the addition of agri-food industry waste (potato peels, chips production waste, expired food in the form of dry farinaceous waste, as well as beet and apple pomace).

During sampling, an intact sample procedure was applied. The sample was cut using a soil cutting ring, prepared in accordance with the soil cultivation methodology. The testing procedure, using the intact sample method, was based, first of all, on measuring the dimensions of the cutting ring with a caliper, in particular the height $[\mathrm{cm}]$ and the inner diameter of the given ring [cm]. Next, the empty ring [g] was weighed. Then the cutting ring was pressed into the soil sample so that no gaps formed between the cut sample and the wall of the ring. The filled ring was cleaned from the outside, and the collected soil was leveled with the edges of the ring by cutting off the soil with a cutting tool from the inside of the ring to the outside. The scheme of the testing procedure was based first of all, on weighing the sample taken on a laboratory scale with accuracy of $0.01 \mathrm{~g}$. For a sample in the form of a prism, the length of each wall was measured along the edge and close to the center of the lateral surface, with accuracy to $0.1 \mathrm{~mm}$.

In the case of a soil sample with cylindrical dimensions, the diameter was measured in two perpendicular directions, also with accuracy to $0.1 \mathrm{~mm}$, in the center and on each edge. The length of each sample was measured three times, with accuracy to $0.1 \mathrm{~mm}$. For a sample in the form of a cylinder, which is prone to deformation during removal from the sampler, the length of the sampler [cm], the internal diameter of the sampler $[\mathrm{cm}]$ and the distance from the end of the sampler to the cut ends of the sample $[\mathrm{cm}]$ were measured. The mass was determined by weighing the sample together with the sampler $[\mathrm{g}]$, and the sampler itself $[\mathrm{g}]$.

For a sample in the cutting ring, the ring was weighed together with the soil sample in the ring [g]. Figure 1 shows a diagram of a cutting ring for sampling intact soil samples. 


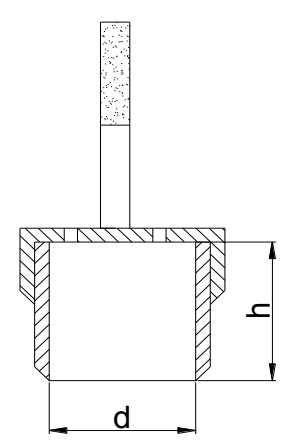

Fig. 1. Diagram of the sampling ring for collecting intact soil samples.

The ring head with guide cylinder is used to fill the ring for hard soil structures on the surface, as well as in profiled depressions. The cutting probe ring is pressed in the head with a support ring. The cylinder guarantees that the sampling is done in a straight line [1].

Determining volumetric density in a natural system was performed based on the following equation.

$$
\lambda_{0}=\frac{\mathrm{M}}{\mathrm{V}},\left[\mathrm{g} \cdot \mathrm{cm}^{-3}\right]
$$

where:

$\mathrm{M}$ - intact structure sample mass [g],

$\mathrm{V}$ - sample volume [cm3].

Real density $\lambda_{0}$ of the soil, dried at $105^{\circ} \mathrm{C}$,

Temporary density $\lambda_{0}$ of the soil, with water content,

$\lambda_{0}$ clay and loamy soils $-1.00-1.60\left[\mathrm{~g} \cdot \mathrm{cm}^{-3}\right]$.

$\lambda_{0}$ sandy soils $-1.20-1.80\left[\mathrm{~g} \cdot \mathrm{cm}^{-3}\right]$.

\section{Findings}

To study the effect of biochar addition on the volumetric density of the soil with simultaneous fertilization with a digestate from an agricultural biogas plant, ten experimental fields in triplicate were prepared, in accordance with agricultural culture. In the first phase, the volumetric density was analyzed only for the soil with the addition of biochar applied in appropriate doses. In the second phase, the effect of fertilization with digestate from an agricultural biogas plant on the volumetric density of the soil was analyzed, at identical biochar doses. The results, i.e. volumetric densities without biochar application, volumetric densities with the addition of biochar, and volumetric densities after fertilization with agricultural digestate, were compared against each other.

In the first year of the experiment, 10 biochar doses per hectare (from 0 to $100 \mathrm{t} / \mathrm{ha}$ ) were assumed, in order to indicate which doses significantly differentiate the volumetric density of the soil. The analysis from the first year of research allowed determining the doses that significantly affect the volumetric density of soil (Table 1). After biochar 
application, the soil was fertilized with digestate in amounts sufficient to achieve the starting dose of nitrogen for legumes. The doses are presented in Table 1

Table 1. Determination of biochar and agricultural digestate doses in the experiment

\begin{tabular}{cccc}
\hline & Biochar & \multicolumn{2}{c}{ Agricultural digestate } \\
\hline Symbol & Dose $\left[\mathrm{t} \cdot \mathrm{ha}^{-1}\right]$ & Symbol & Dose $\left[\mathrm{Nka} \cdot \mathrm{ha}^{-1}\right]$ \\
\hline 0B & 0 & OP & 0 \\
\hline 1B & 40 & 1P & 10 \\
\hline 2B & 60 & 2P & 15 \\
\hline 3B & 80 & 3P & 20 \\
\hline
\end{tabular}

Table 2. Results of variance analysis in a single classification. The volumetric density of the soil, depending on the dose of biochar and on digestate fertilization

\begin{tabular}{lcccc}
\hline Grouping variable & Sum of squares & Mean of squares & Test F & $\mathrm{p}$ \\
\hline $\begin{array}{c}\text { Biochar dose and } \\
\text { digestate } \\
\text { fertilization }\end{array}$ & 0.93213 & Volumetric density of the soil & \\
\cline { 2 - 4 } & 0.10357 & 11.859 & $0,000^{*}$ \\
\hline
\end{tabular}

* significant dependence at $\alpha=0.05$

The variance analysis in a single classification demonstrated that the dose of biochar and fertilization with digestate from agricultural biogas plants statistically significantly differentiates the volumetric density of the soil. 


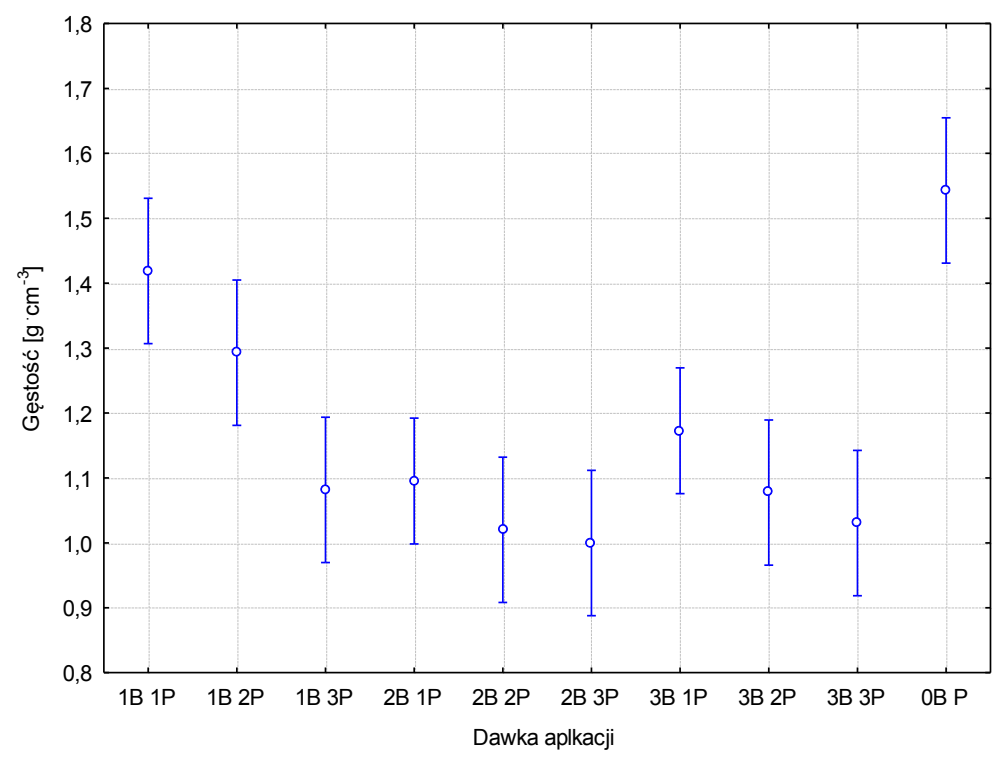

Fig. 2. Average values of the volumetric density of the soil, depending on the dose of biochar and digestate fertilization

Figure 2 is a graphic presentation of the results of the variance analysis of the singlefactor volumetric density of the soil, depending on the dose of biochar and fertilization with agricultural digestate. The applied doses of biochar and digestate significantly reduce the volumetric density. Increasing the applied dose of digestate from an agricultural biogas plant for identical doses of biochar reduces the volumetric density of soil.

Table 3. Duncan test results for significantly different groups, as per the biochar doses and digestate fertilization in volumetric density of the soil as the grouping factor

\begin{tabular}{|c|c|c|c|c|c|c|c|c|c|c|}
\hline & 1B 1P & $1 \mathrm{~B} 2 \mathrm{P}$ & 1B 3P & 2B 1P & $2 \mathrm{~B} 2 \mathrm{P}$ & 2B 3P & 3B 1P & $3 \mathrm{~B} 2 \mathrm{P}$ & 3B 3P & 0B P \\
\hline 1B 1P & & 0.105 & 0.000 & 0.000 & 0.000 & 0.000 & 0.004 & 0.000 & 0.000 & 0.110 \\
\hline 1B 2P & & & 0.015 & 0.019 & 0.003 & 0.002 & 0.121 & 0.015 & 0.004 & 0.004 \\
\hline 1B 3P & & & & 0.856 & 0.458 & 0.335 & 0.259 & 0.956 & 0.524 & 0.000 \\
\hline 2B 1P & & & & & 0.375 & 0.268 & 0.309 & 0.824 & 0.435 & 0.000 \\
\hline 2B $2 \mathrm{P}$ & & & & & & 0.787 & 0.082 & 0.474 & 0.890 & 0.000 \\
\hline 2B 3P & & & & & & & 0.052 & 0.350 & 0.700 & 0.000 \\
\hline $3 \mathrm{~B} 1 \mathrm{P}$ & & & & & & & & 0.254 & 0.099 & 0.000 \\
\hline $3 \mathrm{~B} 2 \mathrm{P}$ & & & & & & & & & 0.534 & 0.000 \\
\hline 3B 3P & & & & & & & & & & 0.000 \\
\hline 0B P & & & & & & & & & & \\
\hline
\end{tabular}

The Duncan test allowed determining for which doses of biochar and agricultural digestate there were statistically significant differences in the volumetric density of the soil. 
The Duncan test confirmed the contextual analysis related to the reduction of the value of volumetric density, depending on the increase in the applied doses of biochar and agricultural digestate.

Table 4. Results of variance analysis in a single classification. The volumetric density of the soil, depending on the dose of biochar and on digestate fertilization

\begin{tabular}{lllll}
\hline Grouping variable & Square sum & Square mean & Test F & $\mathrm{p}$ \\
\hline $\begin{array}{l}\text { Biochar dose and } \\
\text { digestate } \\
\text { fertilization }\end{array}$ & 0.53455 & 0.26728 & 8.7769 & $0,000^{*}$ \\
\cline { 2 - 5 }
\end{tabular}

*- significant dependence at $\alpha=0.05$

The variance analysis in a single classification demonstrated that the dose of biochar and fertilization with digestate from agricultural biogas plants statistically significantly differentiates the volumetric density of the soil.

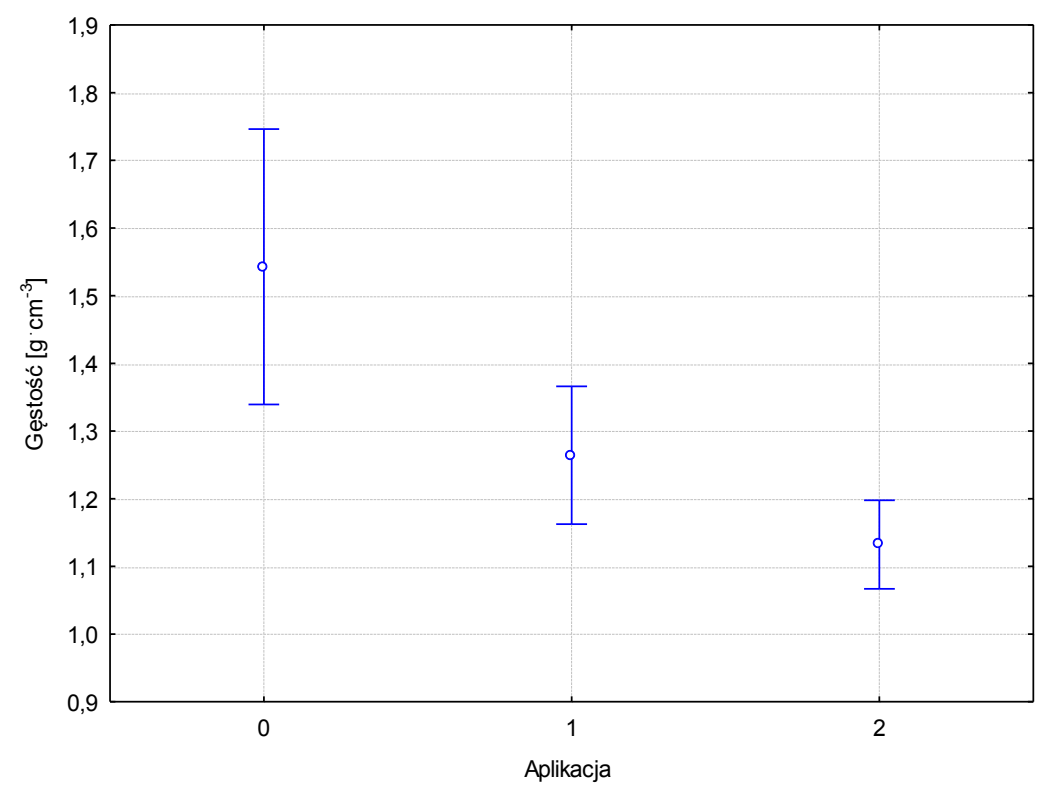

Fig. 3. The values of the volumetric density of the soil, depending on the dose of biochar and digestate fertilization

where:

0 - soil without the addition of biochar and fertilization with agricultural digestate,

1 - soil with the addition of biochar only,

2 - soil with the addition of biochar and fertilization with agricultural digestate.

Figure 3 is a graphic presentation of the variance analysis results for the single-factor volumetric density of the soil, depending on the dose of biochar and fertilization with agricultural digestate. Biochar and digestate application significantly differentiate the 
volume density of the soil. Soil with the addition of biochar and fertilized with agricultural digestate is characterized by the smallest value of volumetric density, as compared to the soil not fertilized, and only with the addition of biochar.

The analysis demonstrated that statistically significant differences in volumetric density of the soil occurred between the soil with neither biochar nor digestate fertilization, and the soil with the addition of biochar, as well as between the soil with biochar and the soil with biochar and digestate.

\section{Conclusion}

The variance analysis in a single classification demonstrated that the dose of biochar and fertilization with digestate from agricultural biogas plants statistically significantly differentiates the volumetric density of the soil. The applied doses of biochar and digestate significantly reduce the volumetric density. Increasing the applied dose of digestate from an agricultural biogas plant for identical doses of biochar reduces the volumetric density of soil. Soil with the addition of biochar and fertilized with agricultural digestate is characterized by the smallest value of volumetric density, as compared to the soil not fertilized, and only with the addition of biochar.

Research on the impact of biochar addition on the volumetric density of the soil with simultaneous fertilization with digestate from agricultural biogas plants demonstrated a positive effect on the soil's individual values. The decrease in the volumetric density value can positively impact the process of field cultivation, as well as on crop yielding. Biochar produced from various substrates can be used to improve the physicochemical properties of soils, which, in turn, will benefit the agricultural sector.

\section{Acknowledgements}

The publication was financed by the National Centre for Research and Development under the strategic program "Natural environment, agriculture and forestry" BIOSTRATEG III (BIOSTRATEG3/345940/7/NCBR/2017).

\section{References}

1. M. Cupiał, A. Szeląg-Sikora, M. Niemiec, M. Agric. Agric. Sci. Proc., 7, 64-6, (2015).

2. K. Mudryk, J. Fraczek, Z. Slipek, S. Francik, W. Wrobel, In Proceedings of 12th International Scientific Conference Engineering for Rural Development, Jelgava, (2013).

3. J. Sikora, M. Niemiec, A. Szelag-Sikora, M. Kubon, E. Olech, and A. Marczuk, Przemysl Chem. 96, 2275-2278 (2017)

4. A. Szelag-Sikora, M. Niemiec, Jakub Sikora, M. Chowaniak, In Proceedings of the IX International Scientific Symposium "Farm Machinery and Processes Management in Sustainable Agriculture, Lublin, 365-370, DOI:10.24326/fmpmsa.2017.65 (2017).

5. Z. Gródek-Szostak, A. Szeląg-Sikora, J. Sikora, M. Korenko, Business and Non-profit Organizations Facing Increased Competition and Growing Customers' Demands (Eds. A Ujwary-Gil, A Nalepka), Wyższa Szkoła Biznesu - National-Louis University, Nowy Sacz, 16, 427-439, (2017).

6. R. Wacławowicz, Problemy Inżynierii Rolniczej 2, 45-49, (2008). 
7. L. Macdonald, M. Farrell, L. van Zwieten, E. Krull, Biology and Fertility of Soils 50 7, (2014).

8. A. Makara, Z. Kowalski, K. Fela, Prace naukowe Akademii im. Jana Długosza w Częstochowie, vol.V, 177- 190, (2017).

9. M. Kuboń, U. Sadowska, A. Klimek-Kopyra, J. Sikora, M. Gliniak, International Multidisciplinary Scientific GeoConference Surveying Geology and Mining Ecology Management, SGEM, 19(5.1), 347-354 (2019).

10. A. Onopiuk, A. Półtorak, J. Wyrwisz, M. Moczkowska, A. Stelmasiak, A. Lipińska,A. Szpicer, M. Zalewska, R. Zaremba, M. Kuboń, A. Wierzbicka, CyTA: journal of food, Volume 15, 1, 58-64 (2017).

11. Z. Grodek-Szostak, G. Malik, D. Kajrunajtys, A. Szelag-Sikora, J. Sikora, M. Kubon, M. Niemiec, J. Kapusta-Duch, Modeling the Dependency between Extreme Prices of Selected Agricultural Products on the Derivatives Market Using the Linkage Function, Sustainability, 11(15), 4144; https://doi.org/10.3390/su11154144 (2019). 